Original Article

\title{
FORMULATION AND OPTIMIZATION OF CURCUMIN SOLID DISPERSION PELLETS FOR IMPROVED SOLUBILITY
}

\section{SANJEEVANI DESHKAR*, ARUN SATPUTE}

Department of Pharmaceutics, Dr. D. Y. Patil Institute of Pharmaceutical Sciences and Research, Pimpri, Pune, 411018, Maharashtra, India Email: sanjeevanisd@yahoo.com

Received: 09 Jul 2019, Revised and Accepted: 12 Oct 2019

\section{ABSTRACT}

Objective: The present study was aimed at designing of solid dispersion based pellets of curcumin $(\mathrm{Cu})$ for improving its solubility.

Methods: Solid dispersion (SD) of Cu was prepared by the melt method using Poloxamer 407 (Pol 407) at a different weight ratio of Cu-Pol 407 (1:2, 1:3, 1:5, 1:7, 1:10). The solid dispersion was characterised by FTIR, SEM, DSC, XRD and evaluated for saturation solubility in water, drug content and in vitro dissolution. The pellets of Cu solid dispersion were prepared by extrusion spheronization technique and optimization was performed by $3^{2}$ full factorial design. The pellets were evaluated for size distribution, flow properties, hardness, disintegration and in vitro drug dissolution.

Results: From the phase solubility analysis, Pol 407 was selected as a Solid dispersion carrier. The formation of Cu-SD by melt method using Pol 407, was confirmed from FTIR and DSC studies. XRD studies indicated a change of Cu from crystalline to amorphous form. There was a significant increase of $\mathrm{Cu}$ when formulated as SD compared to plain $\mathrm{Cu}$. The optimization of extrusion spheronization process revealed the significant effect of $\mathrm{Cu}-\mathrm{Pol} 407$ ratio $(\mathrm{p}<0.0001)$ on in vitro dissolution of pellets. Higher $\mathrm{Cu}$ dissolution was obtained with $\mathrm{Cu}-\mathrm{SD}$ pellets compared to plain $\mathrm{Cu}$ pellets.

Conclusion: The present study demonstrated the potential of Cu-SD pellets in improving the solubility of poorly soluble $\mathrm{Cu}$.

Keywords: Curcumin, Poloxamer, Solid dispersion, Pluronic, Factorial design

(C) 2020 The Authors. Published by Innovare Academic Sciences Pvt Ltd. This is an open-access article under the CC BY license (http://creativecommons.org/licenses/by/4.0/) DOI: http://dx.doi.org/10.22159/ijap.2020v12i2.34846. Journal homepage: https://innovareacademics.in/journals/index.php/ijap

\section{INTRODUCTION}

Curcumin $(\mathrm{Cu})$ is a phenolic phytoconstituent from the curcuminoid group and is obtained from curcuma Longa (family, zingiberaceae), traditionally known as turmeric. It is widely used in Indian and Chinese traditional medicine [1] and also has been extensively studied for its anti-inflammatory [2], anticancer [3], antioxidants [4], antibacterial and wound healing activity [5]. The efficacy of $\mathrm{Cu}$ in hepatoprotection [1], inflammatory bowel disease [4] and lifestyle associated diseases is also reported. The clinical potential of $\mathrm{Cu}$ is limited owing to its low aqueous solubility and poor permeation resulting in lower bioavailability and extensive metabolism. As a result, $\mathrm{Cu}$ is classified into the BCS Class IV compound and its therapeutic potential is limited due to its instability in physiological conditions[6]. Various formulation approaches have been extensively utilized to address the problems of solubility and permeability of $\mathrm{Cu}$, out of which, improving solubility and dissolution of $\mathrm{Cu}$ has been a major area of interest. Solid dispersion (SD) of $\mathrm{Cu}$ using various water-soluble polymers, polyvinylpyrrolidone (PVP) [7], D $\alpha$-tocopheryl polyethylene glycol 1000 succinate [8], chremophore and polyethylene glycol (PEG), Eudragit E100 [9], carboxymethyl cellulose acetate butyrate [10], hydroxypropyl methylcellulose (HPMC) [11], and hydroxypropyl methylcellulose acetate succinate [12] and polyethylene glycol-15hydroxy stearate (Solutol HS 15) [13] are reported.

However, the efficiency of $\mathrm{Cu}$ to form a stable complex with polymer is questionable and a large amount of polymers are needed to obtain a desirable effect. With the availability of self-emulsifying and surface-active carrier with low melting point, the major focus is now shifted to SD formulation using these carriers. One of the interesting strategy is the combination of nanotechnology and SD [14]. Nanomicellization is achieved with the help of amphiphilic carrier that can solubilize the drug in its hydrophobic core and also helps in improving the drug stability and solubility. Parika et al. [15] Reported self nanomicellizing SD of $\mathrm{Cu}$ using soluplus as the carrier. However, the use of a high amount of polymer in the selfnanomicellizing SD may pose a problem in handling and dispensing of this formulation. As pellets allow great design flexibility, ease of handling, can be easily packed in capsules, free-flowing and therefore commercially preferable, the pellet formulation of solid dispersion can address this problem.

In the present study, we have explored the potential of poloxamer 407 (Pol 407) as a carrier for the solid dispersion (SD) of the $\mathrm{Cu}$. The solid dispersion of $\mathrm{Cu}$ was loaded on the pellet formulation and optimization was performed using design of experiment (DOE). The solid-state characterization of SD was done using FTIR, DSC, XRD AND SEM and the self micellizing properties were confirmed by particle size and zeta potential measurement. Pellet formulation was optimized on the basis of size distribution and in vitro dissolution.

\section{MATERIALS AND METHODS}

\section{Materials}

Curcumin (Phyto Life Science Pvt Ltd Gujrat, India) was received as a gift sample. Hydroxypropyl- $\beta$-cyclodextrin (HP $\beta C D$ ), PVP K30, PEG 6000 , microcrystalline cellulose, lactose, and crosscarmellose Sodium were purchased from Himedia, Mumbai, India. Poloxamer 407 (Pol 407) (Kolliphor P 407, BASF Mumbai) and Poloxamer 188 (Pol 188) (Kolliphor P 188, BASF Mumbai) were received as gift sample. All the solvents of analytical grade were used in the study.

\section{Methods}

\section{Phase solubility analysis}

A series of solutions $(5,10,15,20,25,30 \mathrm{mmol})$ of different carriers, HPßCD, Pol 188, Pol 407, PVP K30, and PEG 6000 were prepared in 0.1 $\mathrm{N}$ HCL. An excess amount of $\mathrm{Cu}$ was added to each carrier solution and the dispersion was kept to achieve equilibrium at $25^{\circ} \mathrm{C}$ for $72 \mathrm{~h}$ with shaking at $100 \mathrm{rpm}$ in an orbital shaker (Remi, CIS24b2, India). The dispersions were filtered through $0.45 \mu$ membrane filter, suitably diluted with $0.1 \mathrm{~N} \mathrm{HCL}$ and the drug concentration in solution was analyzed at $429 \mathrm{~nm}$ by UV spectrophotometry (Shimadzu, UV 1700, Japan). The experiment was performed in triplicate $[16,17]$.

\section{Preparation of solid dispersion by melt method}

Solid dispersions of $\mathrm{Cu}$ were prepared with different weight ratio, $1: 2,1: 3,1: 5,1: 7$ and 1:10 of Cu-Pol 407. The carrier was melted at $55^{\circ} \mathrm{C}$, and then the $\mathrm{Cu}$ was dispersed to molten carrier with constant 
stirring followed by quick cooling. The obtained dried mass was then passed through sieve \# 85 and stored in a refrigerator at $4{ }^{\circ} \mathrm{C}$ until further use $[18,19]$.

\section{Characterization of Cu-SD}

Solid state characterization of $\mathrm{Cu}-\mathrm{SD}$ and plain $\mathrm{Cu}$ were characterized by FTIR, DSC and XRD. The morphological characterization was done using SEM.

\section{Scanning electron microscopy}

The surface morphology of $\mathrm{Cu}-\mathrm{SD}$ formulation was studied using field emission scanning electron microscopy (FESEM) (FEI, Nova Nano SEM 450, USA). The samples were coated with platinum layer of $20 \mathrm{~nm}$ to make them electrically conductive and the coated samples were then randomly scanned in the FESEM chamber at an acceleration voltage of $5.00 \mathrm{KV}$. The photomicrographs were obtained at different magnifications [16].

\section{FT-IR study}

IR absorption spectra of $\mathrm{Cu}$, its physical mixture with excipients and SD formulation were recorded by potassium bromide dispersion technique in which dry samples and potassium bromide were placed in the sample holder and infrared spectrum was recorded using FTIR Spectrophotometer (Shimadzu, 8400S, Japan) over a range of $400-4000 \mathrm{~cm}^{-1}[20]$.

\section{Differential scanning calorimetry study}

In order to study the physical state of $\mathrm{Cu}$ and Pol 407, DSC (PerkinElmer, DSC 4000, USA) study was conducted for Cu, Pol 407 and $\mathrm{Cu}-\mathrm{SD}$. Accurately, $1 \mathrm{mg}$ sample was weighed and placed in a sealed aluminum pan, and the sample was heated under nitrogen flow $(20 \mathrm{ml} / \mathrm{min})$ at a scanning rate of $10^{\circ} \mathrm{C}$ per min from 30 to 350 ${ }^{\circ} \mathrm{C}$. An empty aluminum pan was used as reference [10].

\section{X-ray diffraction study}

X-ray diffraction (Rigaku, Miniflex 600, Japan) was performed using $\mathrm{Cu} \mathrm{K} 2 \alpha$ rays with a voltage of $40 \mathrm{kV}$ and a current of $15 \mathrm{~mA}$. Samples were scanned for $2 \theta$ from $20^{\circ}$ to $80^{\circ}$. Diffraction patterns for $\mathrm{Cu}$, Pol 407 and SD of Cu-Pol 407 were obtained [21].

\section{Characterization of $\mathrm{Cu}$-SD for self-micellizing property}

\section{Particle size measurement}

The particle size of $\mathrm{Cu}-\mathrm{SD}$ was determined using dynamic light scattering (Horiba, SZ 100, Japan). Cu-SD was dissolved in 0.1 N HCL, and ultrasonicated for 10 min followed by measurement at fixed angle of $90^{\circ}$ at $25^{\circ} \mathrm{C}$, carried out in triplicate [22].

\section{Drug content study}

$\mathrm{Cu}-\mathrm{SD}$ equivalent to $5 \mathrm{mg}$ of $\mathrm{Cu}$ was transferred to $50 \mathrm{ml}$ volumetric flask, ultrasonicated to $15 \mathrm{~min}$, and diluted to $50 \mathrm{ml}$ with methanol. The solution was appropriately diluted by methanol and absorbance was noted at maximum wavelength, $419 \mathrm{~nm}$. Drug content was determined using the calibration curve in methanol at the same wavelength. All the trials were done in triplicate $[23,24]$.

\section{Saturation solubility}

The solubility of $\mathrm{Cu}$ and $\mathrm{Cu}-\mathrm{SD}$ was determined in $0.1 \mathrm{~N}$ HCL. An excess amount of the $\mathrm{Cu}$ or $\mathrm{Cu}-\mathrm{SD}$ was added into $5 \mathrm{ml}$ of $0.1 \mathrm{~N} \mathrm{HCL}$ up to saturation. Then the glass vials were placed into a water bath shaker for $72 \mathrm{~h}$ at $37^{\circ} \mathrm{C} \pm 0.5$ and $100 \mathrm{rpm}$. The supernatant solutions were then passed through whatman filter paper and analyzed by UV spectrophotometry at $419 \mathrm{~nm}$. All solubility measurements were performed in triplicate [25].

\section{In vitro dissolution study}

In vitro dissolution study was carried out using USP apparatus I (basket assembly). Accurately weighed sample equivalent to $20 \mathrm{mg}$ of $\mathrm{Cu}$-Pol 407 SD was filled into capsule and placed in a basket of dissolution vessel containing $900 \mathrm{ml}$ of $0.1 \mathrm{~N} \mathrm{HCL}$ as dissolution medium, maintained at $37 \pm 0.5{ }^{\circ} \mathrm{C}$ and $100 \mathrm{rpm}$. At each time interval, $5 \mathrm{ml}$ of the sample was withdrawn and appropriately diluted. The equal volume of fresh dissolution medium was immediately replaced. The concentration of $\mathrm{Cu}$ in the sample was analyzed spectrophotometrically at $429 \mathrm{~nm}$. The dissolution experiments were conducted in triplicate.

\section{Preparation of $\mathrm{Cu}-\mathrm{SD}$ pellets}

The pellets of $\mathrm{Cu}$ and $\mathrm{Cu}$-SD were prepared using extrusion and spheronization technique. The $\mathrm{Cu}$ or $\mathrm{Cu}-\mathrm{SD}$ was mixed with all other excipients, except PVP K30 in a mortar. PVP K30 was dissolved in a mixture of IPA and water (2:1 ratio). The PVP solution was added to the powder mixture to form a damp mass. The wet mass was then passed through sieve number $18(1000 \mu \mathrm{m})$ to obtain cylindrical extrudates. The extrudates were placed in a spheronizer (Shakti, SSP 120 , India) fitted with the cross-hatched plate $(2 \mathrm{~mm})$ and spheronized for $5 \mathrm{~min}$ at varying $\mathrm{rpm}(1100,1200,1300 \mathrm{rpm})$. The resulting pellets were dried at $30{ }^{\circ} \mathrm{C}$ in a vacuum oven (Bio technique, BTI29, India) for $30 \mathrm{~min}$ [27]. The composition of pellet formulation is shown in table 1 .

Table 1: Composition of Cu-SD pellets

\begin{tabular}{ll}
\hline Ingredient & Quantity (\%w/w) \\
\hline Solid dispersion (Cu-Pol 407) powder & 30 \\
Microcrystalline cellulose & 30 \\
Lactose & 30 \\
Sodium croscarmellose, & 5 \\
Polyvinyl pyrrolidone K30 & 5 \\
Isopropyl Alcohol and Distilled water & Quantity Sufficient (2:1 ratio) \\
\hline
\end{tabular}

Table 2: $3^{2}$ full factorial design for optimization of $\mathrm{Cu}$-SD pellets

\begin{tabular}{llll}
\hline Run & Batches & (X1) (Cu-Pol 407 ratio) & (X2) (Speed in rpm) \\
\hline 1 & F1 & $-1(1: 0)$ & $-1(1100)$ \\
2 & F2 & $-1(1: 0)$ & $0(1200)$ \\
3 & F3 & $-1(1: 0)$ & $1(1300)$ \\
4 & F4 & $0(1: 3)$ & $0(1100)$ \\
5 & F5 & $0(1: 3)$ & $1(1300)$ \\
6 & F6 & $0(1: 3)$ & $-1(1100)$ \\
7 & F7 & $1(1: 7)$ & $0(1200)$ \\
8 & F8 & $1(1: 7)$ & $1(1300)$ \\
9 & F9 & $1(1: 7)$ &
\end{tabular}

\section{Experimental design}

The optimization of the formulation was performed using $3^{2}$ full factorial design. The design consisted of 2 variables at 3 levels. The first independent variable $\left(\mathrm{X}_{1}\right)$ was $\mathrm{Cu}-\mathrm{Pol} 407$ ratio, $(1: 0,1: 3,1: 7)$ and the other variable $\left(X_{2}\right)$ was spheronization speed $(1100,1200$, $1300 \mathrm{rpm}$ ). Total of nine formulations were prepared (table 2) and the effect on geometric mean diameter $\left(\mathrm{Y}_{1}\right)$ of pellets, and drug 
release after $2 \mathrm{~h}\left(\mathrm{Y}_{2}\right)$ was evaluated. The data from 9 trial runs was analyzed using Design-Expert software (Stat-Ease, version 9.0, USA). The contour plots and 3-D surface response plots were generated in order to study the influence of independent variables on responses.

\section{Characterization of $\mathrm{Cu}$-SD pellet}

\section{Particle size distribution}

The particle size distribution of pellets was carried out by sieve analysis, using a set of USP standard sieves. Sieves set of \#12,16, 18, $22,24,30,36$ and 44 were used along with a pellet load of $10 \mathrm{~g}$. The sieve set was then mechanically shaken for $10 \mathrm{~min}$. The net weight retained on each sieve was determined and these values were used for calculation of the particle size distribution [28].

\section{Scanning electron microscopy}

The surface morphology of $\mathrm{Cu}$-SD pellet formulation was studied using field emission scanning electron microscopy (FESEM) (FEI, Nova Nano SEM 450, USA). The samples were coated with a platinum layer of $20 \mathrm{~nm}$ to make them electrically conductive and the coated samples were then randomly scanned in the FESEM chamber at an acceleration voltage of $5.00 \mathrm{KV}$. The photomicrographs were obtained at different magnifications

\section{Micromeritic properties}

Micromeritic properties like bulk and tapped density, Carr's index, compressibility index and angle of repose of pellet formulation were evaluated as per standard procedure mentioned in USP [28].

\section{Hardness}

The measurement of Hardness of pellets was done using a digital hardness tester (Veego, India).

\section{Drug content}

Drug content of pellets was estimated using UV visible spectrophotometric method. Pellets were crushed to powder using mortar and pestle. Finely crushed sample equivalent to $5 \mathrm{mg}$ of $\mathrm{Cu}$ was transferred to $50 \mathrm{ml}$ methanol, ultrasonicated to $15 \mathrm{~min}$ and after appropriate dilution, absorbance was noted at $419 \mathrm{~nm}$. The experiment was performed in triplicate and drug content was calculated using a previously developed calibration curve in methanol [29].

\section{In vitro dissolution study}

In vitro dissolution study of pellets was performed using the same method as mentioned in the characterization of $\mathrm{Cu}-\mathrm{SD}$.

\section{Stability study}

The stability study of pellet formulation was performed at conditions as per ICH guidelines for Zone IV. Pellet sample was filled in capsules, which was further placed in HDPE container. The samples were maintained in the stability chamber with accelerated conditions $\left(40{ }^{\circ} \mathrm{C} \pm 2{ }^{\circ} \mathrm{C}, 75 \pm 5 \% \mathrm{RH}\right)$, and intermediate condition $(30$ ${ }^{\circ} \mathrm{C} \pm 2{ }^{\circ} \mathrm{C}, 65 \pm 5 \%$ ). The sample were analyzed for appearance, drug content and in vitro drug release at 0 and 1 mo time points at both the conditions.

\section{RESULTS AND DISCUSSION}

\section{Phase solubility analysis}

The solubility of $\mathrm{Cu}$ in $0.1 \mathrm{~N}$ HCL was observed as $0.0018 \mathrm{mmol}$. With increasing carrier concentration over the range of 5 to $30 \mathrm{mmol}$, the $\mathrm{Cu}$ solubility was found to be increased in a linear fashion in all the carriers as shown in fig. 1. The sudden increase in solubility was observed with Pol 407 and PVP K30 as compared to other carriers. At $30 \mathrm{mmol}$ concentration of Pol 407, the solubility of $\mathrm{Cu}$ was observed as $1.659 \mathrm{mmol}$. Thus, 921.6 fold increase in solubility of $\mathrm{Cu}$ was observed. Pol 407 is an amphiphilic coblock polymer with a large number of polyethylene oxide chains representing hydrophilic portion and polypropylene oxide units representing the hydrophobic part. At higher concentrations, it forms micelles, thus allowing solubilization of hydrophobic drugs in its core resulting in improved drug solubility. Considering this, for further study, Pol 407 was selected as SD carrier.

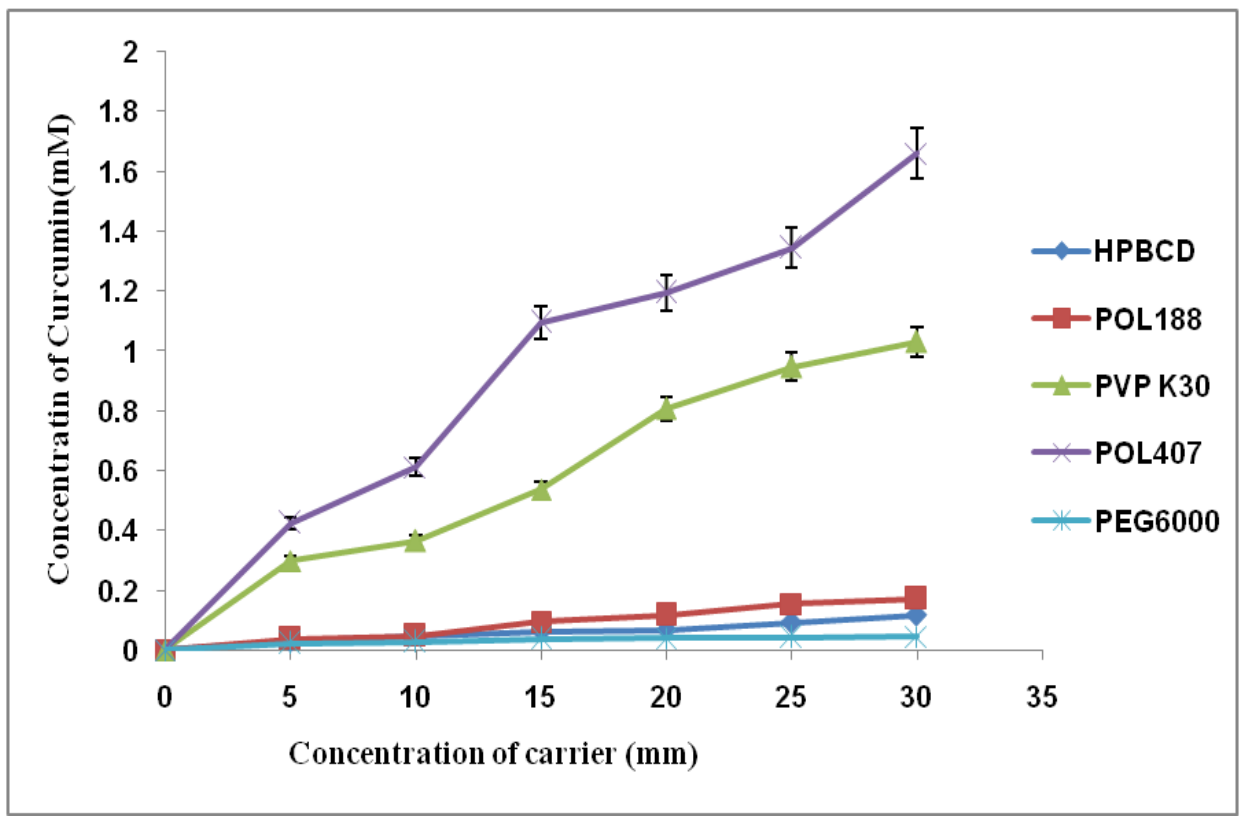

Fig. 1: Phase solubility analysis of $\mathrm{Cu}$ in different carriers, *error bars represent standard deviations of three replicates

\section{Formulation and evaluation of $\mathrm{Cu}-\mathrm{SD}$}

From the phase solubility plots, considering the high molecular weight of Pol 407, Cu solid dispersions were prepared with $\mathrm{Cu}-$ Pol 407 weight ratio of 1:2, 1:3, 1:5, 1:7, 1:10 instead of molar ratio.

\section{Scanning electron microscopy}

Scanning electron micrograph of $\mathrm{Cu}$ revealed its crystalline structure and Pol 407 appeared as perfectly spherical smooth-surfaced particles (fig. 2). The SEM of Cu-SD showed agglomerated particles with a rough surface. 


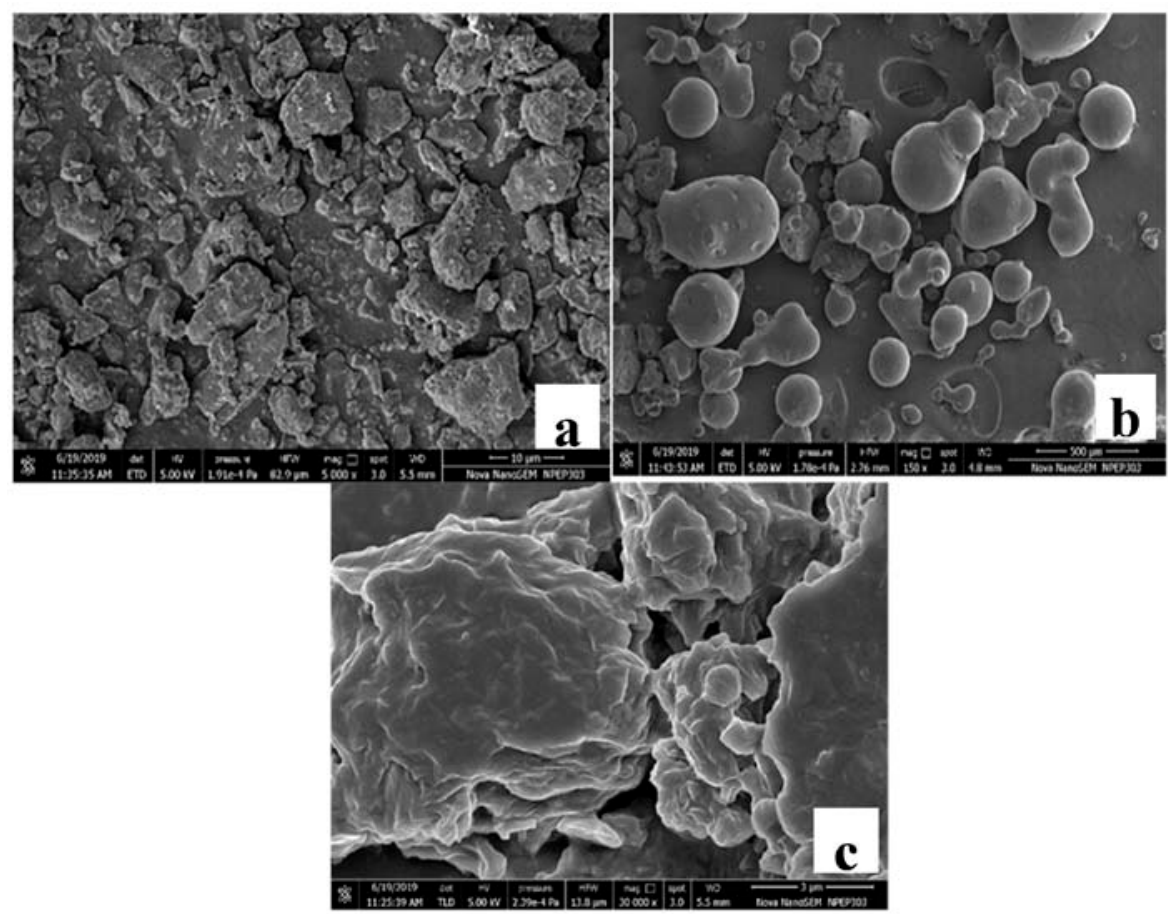

Fig. 2: Scanning electron micrograph of (a) Cu (b) Pol 407 (c) Cu-SD

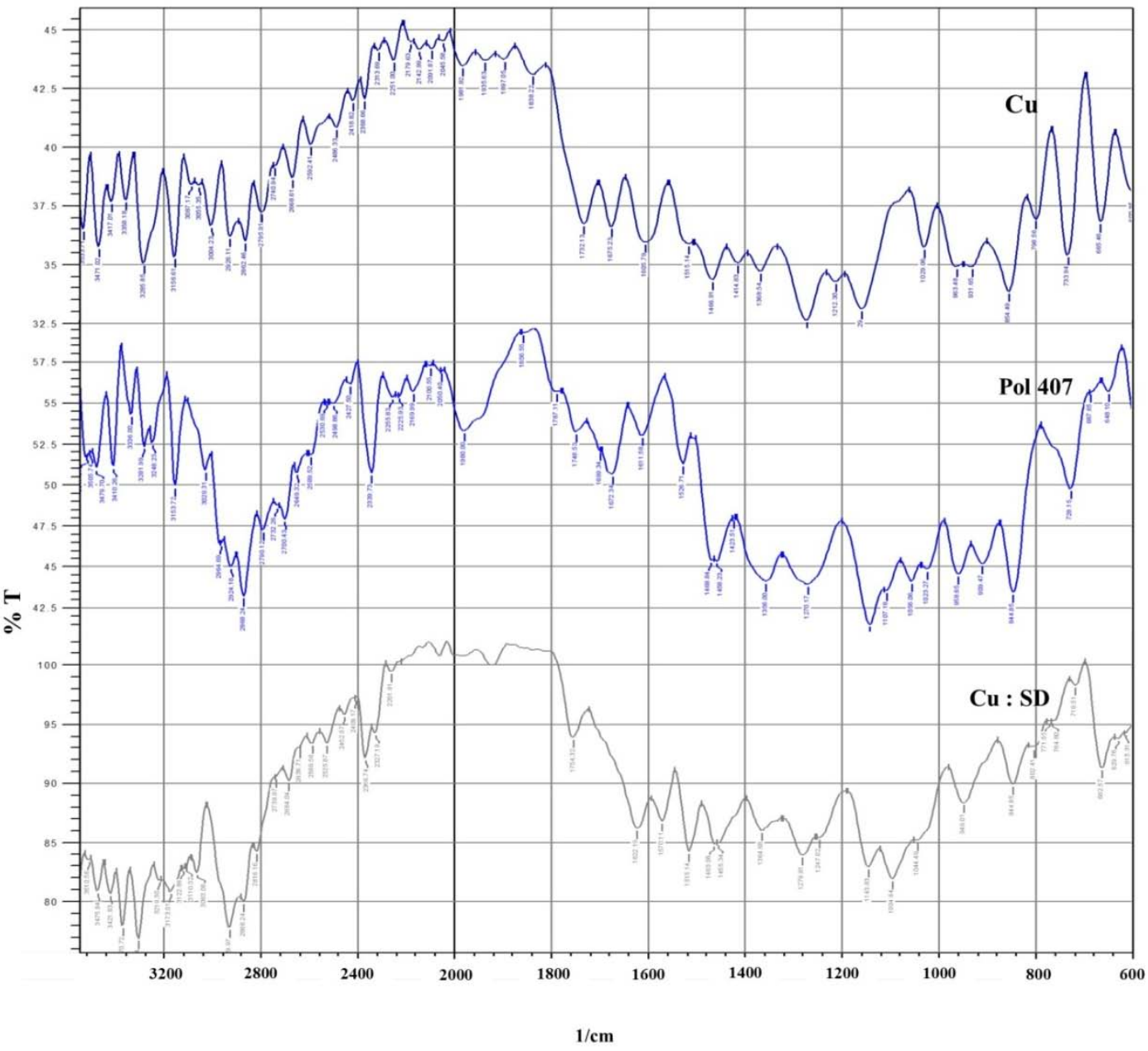

Fig. 3: FTIR spectra of (a) Cu (b) Pol 407 (c) Cu-SD 


\section{FT-IR study}

The IR spectra of pure $\mathrm{Cu}$ (fig. 3) presented characteristic peaks at 3471.02-3285.85 cm-1 (O-H stretching), $3156.61 \mathrm{~cm}^{-1} \quad$ (C-H stretching), $3004.23 \mathrm{~cm}^{-1}$ (aromatic C-H stretching), 2926.11$2862.46 \mathrm{~cm}^{-1}$ (asymmetric symmetric stretching of $-\mathrm{CH}_{3}$ group), 1732.13-1675.23 $\mathrm{cm}^{-1}(\mathrm{C}=\mathrm{O}$ and $\mathrm{C}=\mathrm{C}$ stretching in aromatic) and $733.94 \mathrm{~cm}^{-1}$ (C-H bonding of aromatic group). The IR spectra of pure Pol 407 showed peaks at 3153.72 (O-H group stretching), 2924.18$2868.24 \mathrm{~cm}^{-1}$ (asymmetric and symmetric Stretching of- $\mathrm{CH}_{3}$ and $\mathrm{CH}_{2}$ group) and $1140.93 \mathrm{~cm}^{-1}$ (C-0 Single bond stretching).

$\mathrm{Cu}$ in its free form has two hydroxyl group with their frequencies at $3471.02-3285.85 \mathrm{~cm}^{-1}$ and Pol 407 has one hydroxyl group at
$3153.72 \mathrm{~cm}^{-1}$. In the IR spectra of $\mathrm{Cu}-\mathrm{SD}$, the decrease in the frequencies of hydroxyl group in the range $3510.56-3173.01 \mathrm{~cm}^{-1}$ is attributed to hydrogen bonding between $\mathrm{Cu}$ and Pol 407. This confirms the $\mathrm{Cu}$ and Pol 407 interactions during the formation of Solid dispersion.

\section{Differential scanning calorimetry study}

The solid-state changes in Cu-SD were studied by comparing DSC of $\mathrm{Cu}$, Pol 407, and $\mathrm{Cu}-\mathrm{Pol} 407$ SD (fig. 4). The crystallinity in $\mathrm{Cu}$ was confirmed by sharp endothermic peak at $178.66^{\circ} \mathrm{C}$. DSC of Pol 407 demonstrated endotherm at $54.9^{\circ} \mathrm{C}$. The endothermic peak was observed at $53.16{ }^{\circ} \mathrm{C}$ in $\mathrm{Cu}-\mathrm{SD}$. The peak for $\mathrm{Cu}$ was not observed. This confirmed molecular dispersion of $\mathrm{Cu}$ in Pol 407 carrier.

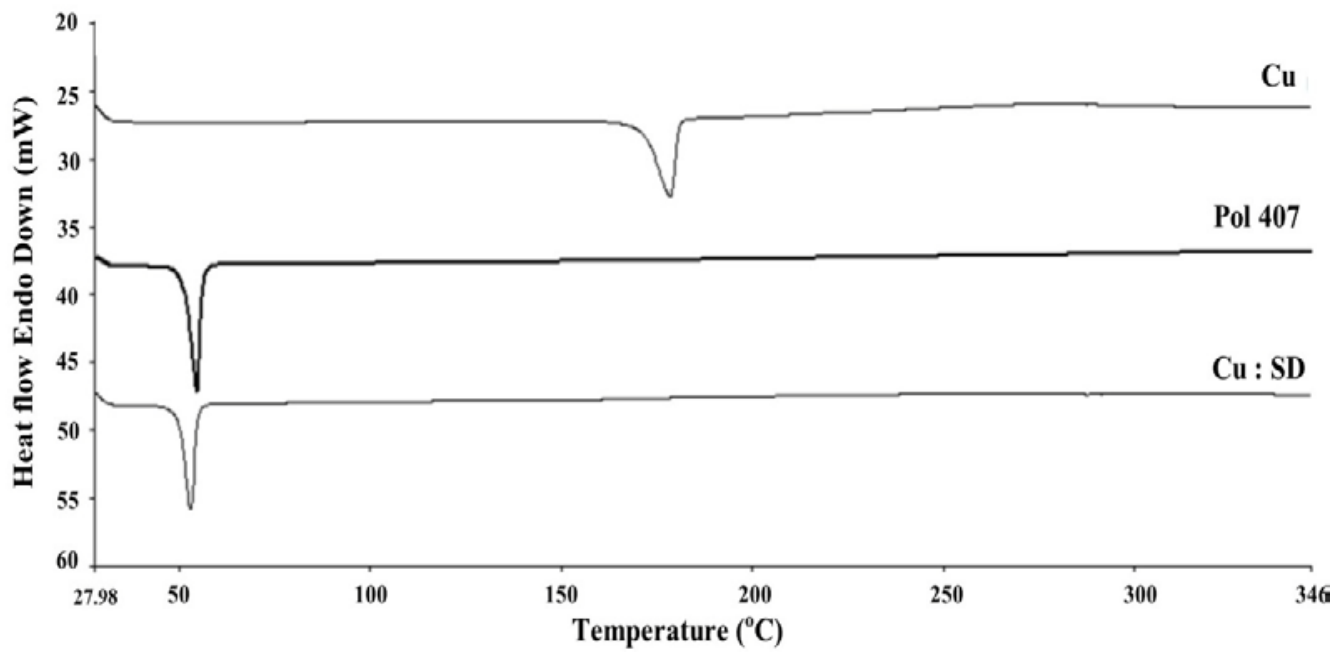

Fig. 4: Differential scanning calorimetry of (a) Cu (b) Pol 407 (c) Cu-SD

\section{X-ray diffraction study}

The changes in the crystallinity of $\mathrm{Cu}$ in SD formulation were further confirmed by XRD. Fig. 5 represents X-Ray diffractogram of $\mathrm{Cu}$, Pol 407, and $\mathrm{Cu}-\mathrm{SD}$. The sharp characteristic peaks of $\mathrm{Cu}$ were observed at $2 \theta$, $21.12^{\circ}, 23.3^{\circ}, 25.52^{\circ}, 25.56^{\circ}$, and $28.92^{\circ}$ in raw Cu sample. This confirmed the crystalline nature of $\mathrm{Cu}$. Pol 407 indicated a sharp peak in the range, $22.88^{\circ}$ to $23.78^{\circ}$. In Cu-SD sample, the sharp peaks of Pol 407 in the range of $23.12{ }^{\circ}$ to $23.82{ }^{\circ}$ were observed but there was a complete disappearance of Cu peaks. This indicated a complete change of $\mathrm{Cu}$ from crystalline to amorphous form. This can be correlated with the enhanced solubility and dissolution of $\mathrm{Cu}-\mathrm{SD}$ as compared to raw $\mathrm{Cu}$.

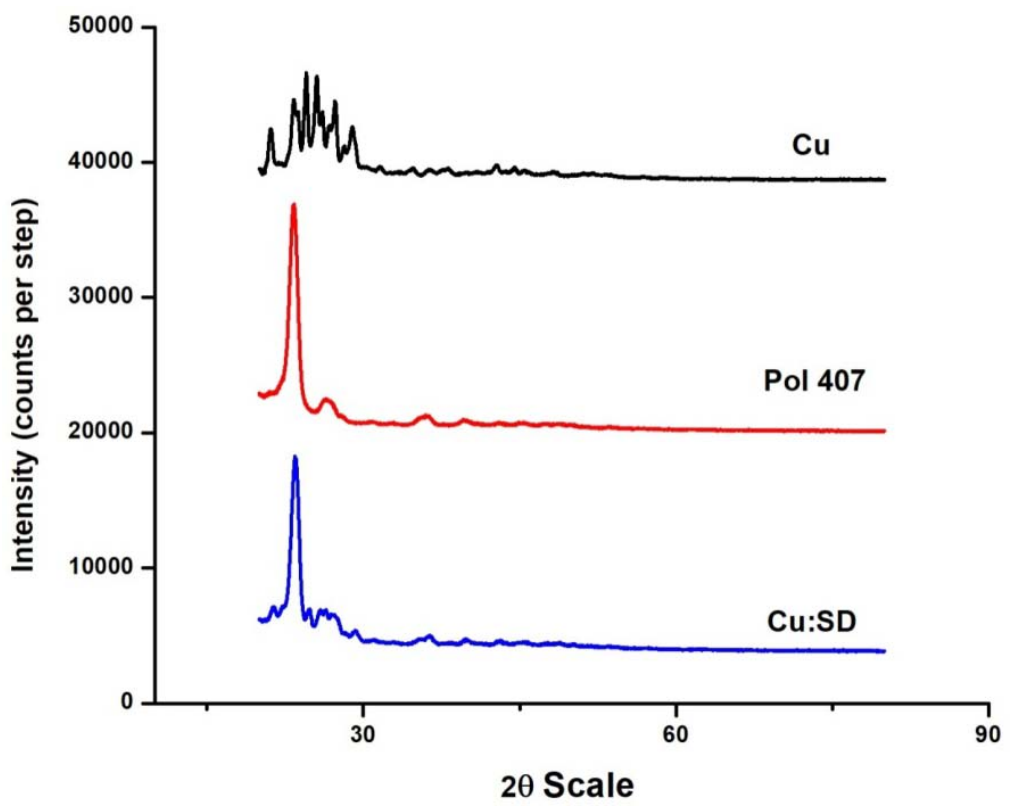

Fig. 5: XRD of (a) Cu (b) Pol 407 (c) Cu-SD 


\section{Characterization of $\mathrm{Cu}-\mathrm{SD}$ for self micellizing property}

Pol 407 is a block copolymer with poly (ethylene oxide) (PEO) and poly (propylene oxide) (PPO) units. Above critical micelle concentration of $2.8 \times 10^{-6} \mathrm{M}$ at $37^{\circ} \mathrm{C}$ it forms micelles with PPO unit aggregated in the core and PEO units oriented towards the external aqueous phase. Micellar solubilization of lipophilic drugs could result in an increase in drug solubility. In order to confirm the formation of micelles by Pol 407, the particle size distribution was conducted after dispersion of SD in water (table 3).

The solid dispersion formulation showed mean size of micelles in the range 721.4 to $1311.7 \mathrm{~nm}$ and PDI in range 0.409 to 1.612. Parikh et al. [15] reported similar nanomicellizing formulations where the size of micelles was obtained as $63.05 \pm 5.24 \mathrm{~nm}$ with polydispersity index of $0.09 \pm 0.04$. In these formulations they used Soluplus and Solutol HS-15 as polymers. The higher values of the polydispersity index in our reported formulations could be the result of excessive Pol 407 present in higher $\mathrm{Cu}-\mathrm{Pol} 407$ ratios. High concentration of Pol 407 may result in increase in number of micelles and their size. This could result in uneven size distribution of micelles. The drug content of $\mathrm{Cu}-\mathrm{SD}$ was found to be in range 81.56 to $92.02 \%$.

\section{Saturation solubility}

The result of saturation solubility is depicted in fig. 6. The SD with ratio 1:3 demonstrated significant increase in solubility of $\mathrm{Cu}$ $(158.71 \mathrm{mg} / \mathrm{ml})$ as compared to only $\mathrm{Cu}(0.692 \mathrm{mg} / \mathrm{ml})$ and SD with ratio $1: 7$ demonstrated solubility value of $333.72 \mathrm{mg} / \mathrm{ml}$. Thus, the solubility of $\mathrm{Cu}$ was significantly increased with increasing ratio of $\mathrm{Cu}$-Pol 407. This could be attributed to increase in formation of micelles with increase in $\mathrm{Cu}-\mathrm{Pol} 407$ ratio.

Table 3: Characterization of Cu-SD for particle size and drug content

\begin{tabular}{llll}
\hline Batch & Mean size (d90) (nm) & PDI & Drug content (\%) $^{*}$ \\
\hline SD1 & 721.4 & 0.409 & $82.58 \pm 0.78$ \\
SD2 & 878.1 & 0.759 & $86.0 \pm 0.33$ \\
SD3 & 1156.6 & 0.975 & $88.40 \pm 0.20$ \\
SD4 & 1266.6 & 1.015 & $92.27 \pm 0.15$ \\
SD5 & 1311.7 & 1.612 & $93.74 \pm 0.24$ \\
\hline
\end{tabular}

*Values are expressed as mean $\pm \mathrm{SD}(\mathrm{n}=3)$

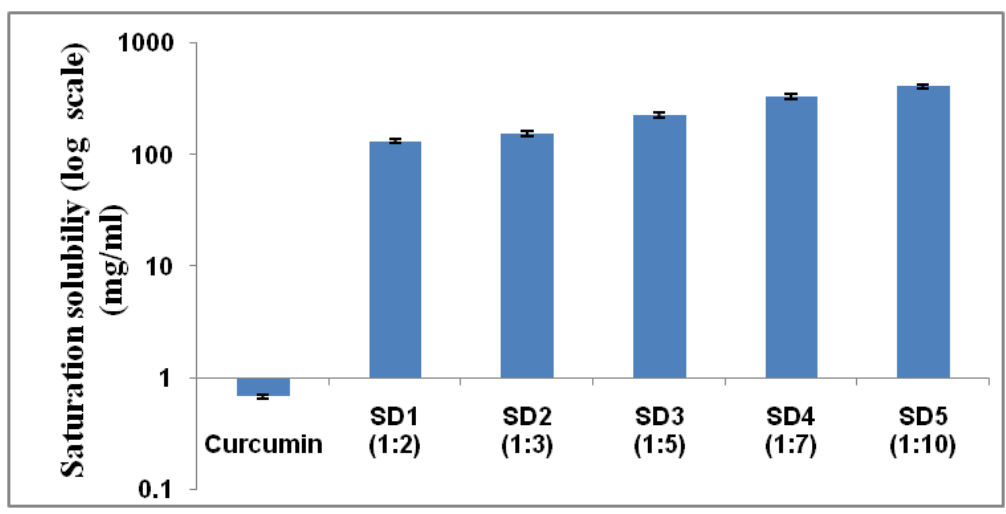

Fig. 6: Saturation solubility $(\mathrm{mg} / \mathrm{ml})(\log$ scale) of $\mathrm{Cu}$ and Cu-SD in $0.1 \mathrm{~N} \mathrm{HCL}$, *error bars represent standard deviations of three replicates

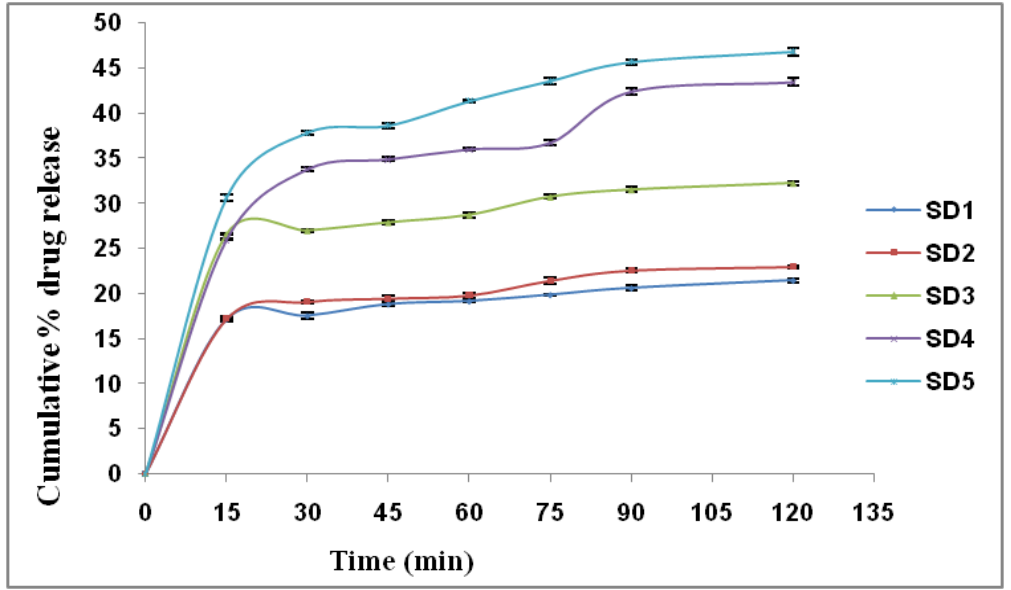

Fig. 7: In vitro dissolution study of Cu-SD formulation, *error bars represent standard deviations of three replicates

\section{In vitro dissolution study of $\mathrm{Cu}-\mathrm{SD}$}

Fig. 7 represents in vitro dissolution of $\mathrm{Cu}$ solid dispersion formulations. $\mathrm{Cu}$-SD demonstrated higher drug release as compared to raw $\mathrm{Cu}$. When $\mathrm{Cu}$-Pol 407 ratio was increased from $1: 2$ to $1: 3$ there was no significant increase in drug release. However, with increase in ratio to $1: 7$ and 1:10, the drug release was significantly increased. This is in agreement with the reports of Paradkar et al. 
[30] in which authors reported a solid dispersion system of $\mathrm{Cu}$ and PVP at different weight ratio. The drug release of solid dispersion was significantly higher than pure $\mathrm{Cu}$ and ratio 1:7 and 1:10 demonstrated a significant increase in drug release as compared to lower ratios, $1: 1,1: 3$ and $1: 5$

Considering the results of saturation solubility, particle size and in vitro dissolution, the solid dispersion ratios of $1: 3$ and $1: 7$ were selected for the formulation of solid dispersion loaded pellets.

\section{Characterization of $\mathrm{Cu}-\mathrm{SD}$ pellets}

Pellet formulations of $\mathrm{Cu}-\mathrm{SD}$ were prepared by extrusion spheronization technique in order to overcome the problems of agglomeration and poor flowability of solid dispersion due to higher poloxamer concentration. Cu-SD was $30 \% \mathrm{w} / \mathrm{w}$ and other excipients were $70 \% \mathrm{w} / \mathrm{w}$ in the pellet formulation. Pellet formulation by extrusion spheronization takes place through various stages, attrition, plastic deformation and agglomeration resulting into shape change from cylindrical dumbbells, ellipsoid to finally spherical shape pellets. Preliminary trials were performed in order to optimize the solvents for the pelletization process. Water: IPA (isopropyl alcohol) in 1:4 ratio was used as solvent. Increase in water proportion resulted in sticky product whereas use of only IPA resulted in friable pellets. From the preliminary trials, the spheronization speed was set in the range of 1100 to $1300 \mathrm{rpm}$.

The feasibility of extrusion spheronization process for the formulation of pellets containing $\mathrm{Cu}$ in free form and in complex form with Pol 407 was studied using Design of Experiments (DOE). (table 4) depicts the effect of independent variables $\mathrm{Cu}-\mathrm{Pol} 407$ ratio $\left(\mathrm{X}_{1}\right)$ and spheronization speed $\left(\mathrm{X}_{2}\right)$ on evaluation parameters. The pellet formulation indicated good flow properties and compressibility as evident from Hausner ratio and compressibility index. As the spheronization speed was increased from 1100 to $1300 \mathrm{rpm}$, there was decrease in the values of angle of repose. For $\mathrm{Cu}$ pellets without SD (1:0 ratio), the $d_{\text {geo }}$ (geometric mean diameter) of pellet increased with increase in spheronization speed (fig. 8). However, with $\mathrm{Cu}-\mathrm{SD}$ pellets, there was no significant change in $d_{\text {geo }}$ with change in spheronization speed. During $\mathrm{Cu}$ pellet formation, higher speed of spheronization resulted in higher attrition producing large amount of fines. These fines, during dumbbell phase got deposited in the waist region resulting in formation of larger pellets. In $\mathrm{Cu}-\mathrm{SD}$ pellet, presence of Pol 407 in high amount imparted excess cohesion and plasticity, thus decreasing the fine production. This resulted in narrow size distribution as compared to only $\mathrm{Cu}$ pellets. At higher speed, due to the deposition of excess fines, the pellet surface was rough resulting into increase in the value of angle of repose. The drug content for all the pellet formulation was in the range 81.69 to $93.69 \%$.

Table 4: Effect of independent variables on responses

\begin{tabular}{llll}
\hline Run & Batches & (Y1) (Geometric mean diameter in $\boldsymbol{\mu m})$ & (Y2) $(\text { Drug release } \%)^{*}$ \\
\hline 1 & F1 & 927.89 & $19.62 \pm 0.32$ \\
2 & F2 & 943.4 & $19.13 \pm 0.07$ \\
3 & F3 & 1066.59 & $18.55 \pm 0.20$ \\
4 & F4 & 954.11 & $51.45 \pm 0.13$ \\
5 & F5 & 955.43 & $51.94 \pm 0.28$ \\
6 & F6 & 934.11 & $52.15 \pm 0.18$ \\
7 & F7 & 916.22 & $56.3 \pm 0.16$ \\
8 & F8 & 905.73 & $58.29 \pm 0.17$ \\
9 & F9 & 964.94 & $57.5 \pm 0.17$ \\
\hline
\end{tabular}

*Values are expressed as mean \pm SD $(n=3)$
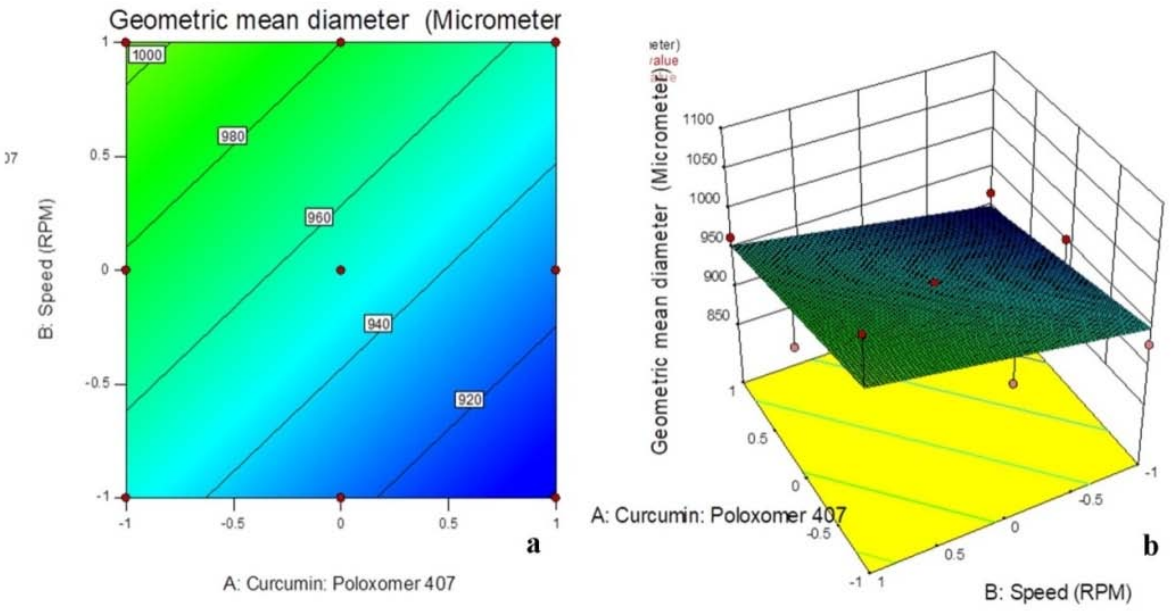

Fig. 8: (a) contour plot (b) Surface response plot showing effect of $\mathrm{Cu}$-Pol 407 ratio and speed on geometric mean diameter

In order to check the relationship between independent variables and the responses, multiple liner regression analysis was carried out. The significance of the model was checked by ANOVA followed by student t-test. Form the ANOVA data, the effect of variables on pellet size was observed as insignificant whereas independent variables contributed significantly $(\mathrm{p}<0.050)$ to drug release after $2 \mathrm{~h}$.

Equation 1 indicated the effect of independent variables on drug release after $2 \mathrm{~h}(\mathrm{Y} 2)$
Drug release $(\%)\left(\mathrm{Y}_{2}\right)=52.2+19.13 \mathrm{X}_{1}+0.14 \mathrm{X}_{2}+0.57 \mathrm{X}_{1} \mathrm{X}_{2}-13.62 \mathrm{X}_{1}{ }^{2-}$
$0.52 \mathrm{X}_{2}{ }^{2-}$

The high $F$ value (1740.31) and $p$ value less than $0.05(p=0.0001)$ imply the significance of the model. The predicted $R^{2}(0.9961)$ was in reasonable agreement with the adjusted $\mathrm{R}^{2}(0.9991)$.

Table 5 indicates ANOVA data for response $Y_{2}$. ANOVA data indicates significant effect of $\mathrm{Cu}-\mathrm{Pol} 407$ on drug release $(\mathrm{p}<0.0001)$. The higher $\mathrm{p}$ 
value $(p>0.1)$ indicated a non-significant effect of spheronization speed on drug release. The presence of quadratic tern in the equation indicated non-linearity in the response. Equation 1 suggested that $X_{1}$ had positive effect on drug release. The effect was further verified from the response surface and the counterplot as shown in (fig. 9). From the surface response plot, it was observed that when $\mathrm{Cu}$-Pol 407 ratio was changed from 1:0 to 1:3, there was significant increase in the drug dissolution. This was due to presence of Pol 407 as solubility enhancer in the solid dispersion. Further increase in $\mathrm{Cu}-\mathrm{Pol} 407$ ratio to 1:7 increased the $\mathrm{Cu}$ dissolution, but the change was not very significant. The drug release from, SD pellets with $\mathrm{Cu}-\mathrm{Pol} 407$ ratio 1:3 was higher as compared to their SD formulation. This could be due to presence of hydrophilic carriers in pellet formulation. In addition, the uniform size of pellets provided a higher surface area for drug release than the agglomerated SD powdered formulations. There was no significant difference in the dissolution of pellets with different $\mathrm{Cu}-\mathrm{Pol} 407$ ratio SD. Change in spheronization speed did not significantly affect the dissolution of pellets.

Table 5: ANOVA data for response $Y_{2}$ (\%Drug release)

\begin{tabular}{|c|c|c|c|c|c|}
\hline \multicolumn{6}{|c|}{ Analysis of variance table [Partial sum of squares-Type III] } \\
\hline Source & Sum of squares & df & Mean square & F value & p-value Prob $>$ F \\
\hline Model & 2568.81 & 5 & 513.76 & 1740.31 & $<0.0001^{*}$ \\
\hline $\mathrm{X}_{1}-\mathrm{Cu}$ : Poloxomer 407 & 2196.12 & 1 & 2196.12 & 7439.09 & $<0.0001^{*}$ \\
\hline $\mathrm{X}_{2}$-Spheronization Speed & 0.11 & 1 & 0.11 & 0.39 & 0.5771 \\
\hline $\mathrm{X}_{1} \mathrm{X}_{2}$ & 1.29 & 1 & 1.29 & 4.36 & 0.1279 \\
\hline $\mathrm{X}_{1}{ }^{2}$ & 370.74 & 1 & 370.74 & 1255.82 & $<0.0001^{*}$ \\
\hline $\mathrm{X}_{2}{ }^{2}$ & 0.55 & 1 & 0.55 & 1.87 & 0.2652 \\
\hline Residual & 0.89 & 3 & 0.30 & & \\
\hline Cor Total & 2569.70 & 8 & & & \\
\hline
\end{tabular}

*indicates significance of the model, Counter plot (fig. 9 A) indicated more than $50 \%$ Cu release for ratio of 1:3 and higher. Fig. 10 indicates dissolution profile of $\mathrm{Cu}$ and $\mathrm{Cu}$-SD pellet.
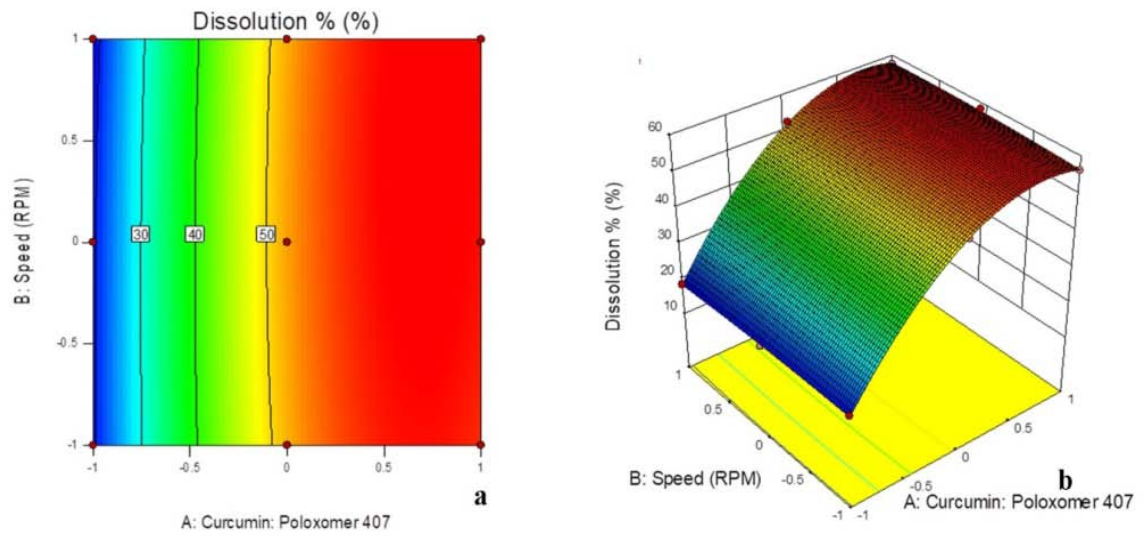

Fig. 9: (a) contour plot (b) Surface response plot showing effect of Cu-Pol 407 ratio and speed on dissolution at $2 \mathrm{~h}$ (\%)

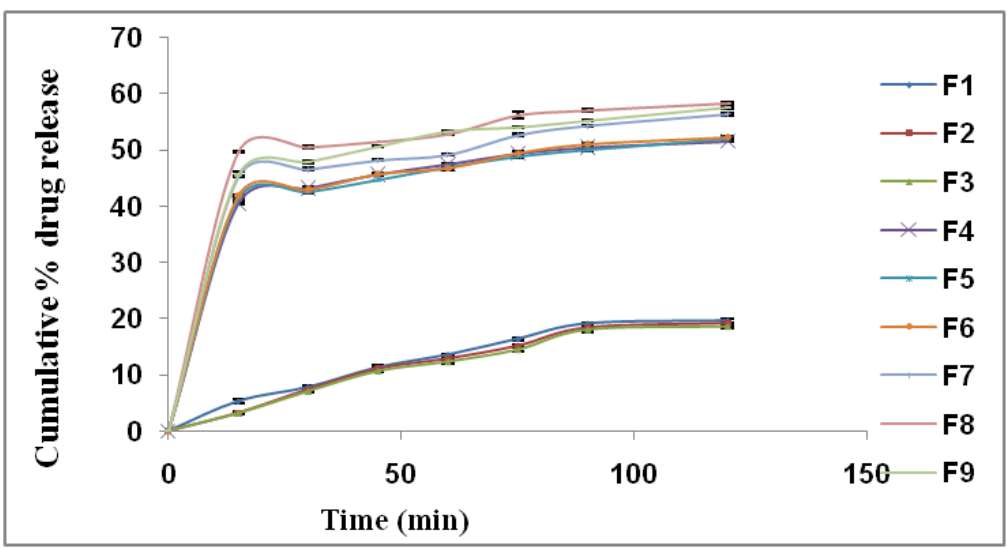

Fig. 10: In vitro dissolution profile of Cu-SD pellet formulation, *error bars represent standard deviations of three replicates

The result of micrometric properties indicated good flow and compressibility properties of pellet formulations (table 6). With increase in $\mathrm{Cu}-\mathrm{Pol} 407$ ratio in pellet formulation to $1: 7$, flow properties were adversely affected. Scanning electron micrograph of pellet formulation (fig. 11) confirmed the spherical shape of pellets. The surface of pellets was found to be rough. This could be due to deposition of fines produced by attrition of pellets during spheronization. These results were in agreement with our observation during the optimization of the pelletization process. 
Table 6: Micromeritic properties of Cu-SD pellets

\begin{tabular}{llllll}
\hline Batch & Bulk density & Tapped density & Hausner's ratio & Carr's index \% & Hardness g/cm3 \\
\hline F1 & $1.05 \pm 0.15$ & $1.01 \pm 0.17$ & $1.03 \pm 0.18$ & $3.8 \pm 0.21$ & $1.230 \pm 0.41$ \\
F2 & $1.06 \pm 0.21$ & $1.14 \pm 0.25$ & $1.07 \pm 0.16$ & $7.01 \pm 0.18$ & $1.310 \pm 0.35$ \\
F3 & $0.87 \pm 0.20$ & $1.14 \pm 0.29$ & $1.12 \pm 020$ & $11.40 \pm 0.39$ & $1.400 \pm 0.42$ \\
F4 & $0.95 \pm 0.25$ & $0.98 \pm 0.31$ & $1.04 \pm 0.22$ & $3.84 \pm 0.24$ & $0.800 \pm 03.39$ \\
F5 & $0.97 \pm 0.15$ & $1.01 \pm 0.18$ & $1.11 \pm 0.19$ & $3.96 \pm 0.15$ & $0.830 \pm 0.5$ \\
F6 & $0.95 \pm 0.32$ & $0.98 \pm 0.30$ & $1.03 \pm 0.24$ & $3.06 \pm 0.42$ & $0.850 \pm 0.25$ \\
F7 & $1.01 \pm 0.27$ & $1.12 \pm 0.16$ & $1.10 \pm 0.32$ & $9.82 \pm 0.25$ & $1.00 \pm 0.45$ \\
F8 & $1.02 \pm 0.29$ & $1.06 \pm 0.28$ & $1.03 \pm 0.37$ & $3.30 \pm 0.36$ & $0.988 \pm 0.58$ \\
F9 & $1.06 \pm 0.38$ & $1.23 \pm 0.35$ & $1.16 \pm 0.27$ & $13.82 \pm 0.21$ & $0.970 \pm 0.25$ \\
\hline
\end{tabular}

*Values are expressed as mean \pm SD $(n=3)$

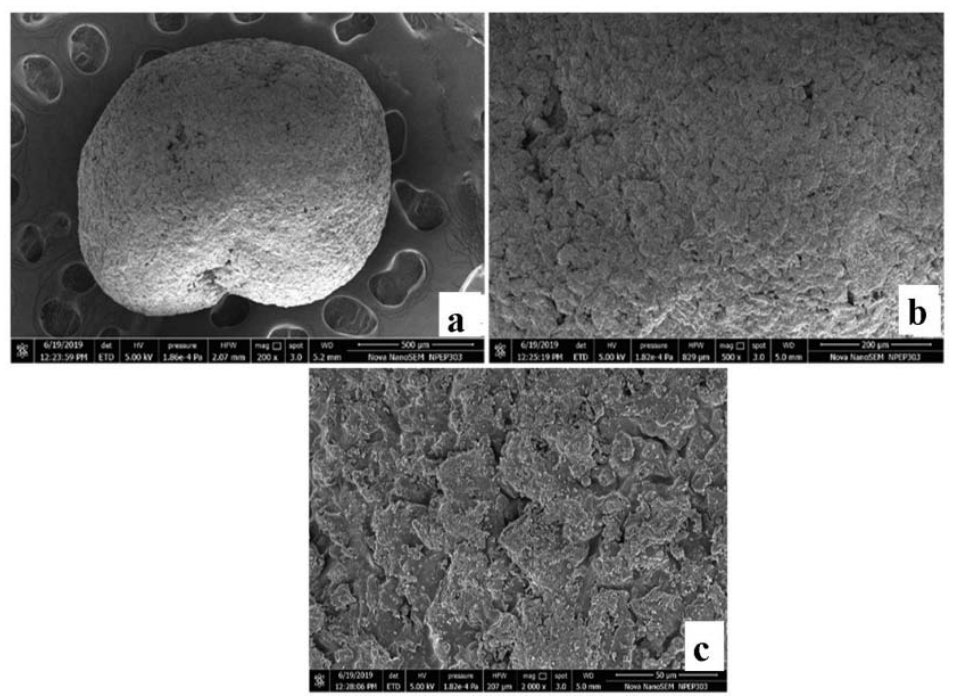

Fig. 11: SEM of the surface of Cu-SD pellet at magnification (a) $200 \mathrm{X}$ (b) $500 \mathrm{X}$ (c) $2000 \mathrm{X}$

\section{Selection of optimized formulation of $\mathrm{Cu}-\mathrm{SD}$ pellets}

The criteria for the selection of optimized formulations were higher drug release and minimum geometric mean diameter. Based on the results of pellet size distribution and in vitro dissolution of pellets, F5 (Cu-Pol 407 ratio 1:3) was selected as an optimized formulation, since at this ratio, the higher release of $\mathrm{Cu}$ was obtained and further change in ratio did not significantly change dissolution profile. Fig. 12 indicates an overlay plot and table 7 indicates a comparison of predicted and experimental results. The percentage error in predicted and experimental values was only $0.14 \%$ and $0.48 \%$ indicating robustness of pellet formulation. This confirms the validation and pellet formulation process.

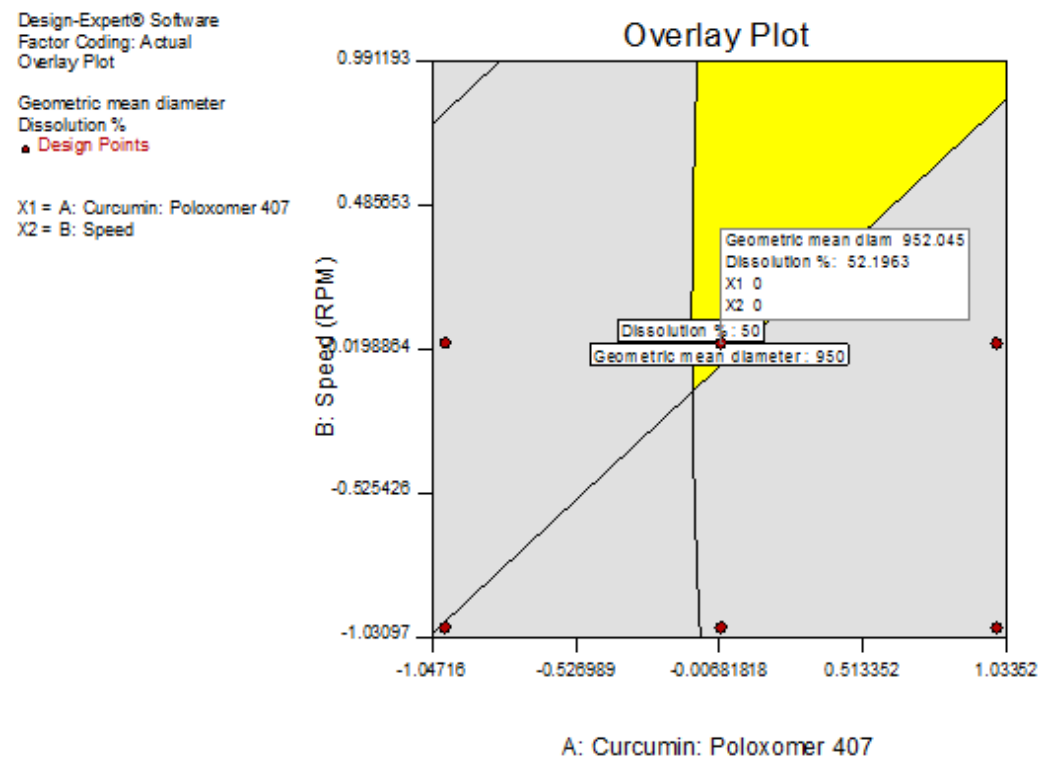

Fig. 12: Overlay plot indicating design space and optimized formulation 
Table 7: Comparison of predicted values and experimental value of optimized formulation

\begin{tabular}{|c|c|c|c|c|c|}
\hline Batch & Factor & Responses & Predicted value & Experimental value & Percentage error \\
\hline & $\mathrm{X} 1 \mathrm{Cu}$-Poloxamer ratio (1:3) & Geometric Mean Dimeter $(\mu \mathrm{m})$ & 952.04 & 955.43 & $0.14 \%$ \\
\hline F5 & X2 Speed (rpm) (1200) & Drug Release after $2 \mathrm{~h}^{*}(\%)$ & $52.19 \pm 0.21$ & $51.94 \pm 0.28$ & $0.48 \%$ \\
\hline
\end{tabular}

*Values are expressed as mean $\pm \mathrm{SD}(\mathrm{n}=3)$

Table 8: Stability data of Cu-SD pellet formulation

\begin{tabular}{|c|c|c|c|c|}
\hline & \multicolumn{2}{|c|}{$30{ }^{\circ} \mathrm{C} \pm 2{ }^{\circ} \mathrm{C}, 65 \pm 5 \%$} & \multicolumn{2}{|c|}{$40{ }^{\circ} \mathrm{C} \pm 2{ }^{\circ} \mathrm{C}, 75 \pm 5 \% \mathrm{RH}$} \\
\hline & $\mathbf{0 ~ d}$ & $1 \mathrm{mo}$ & O D & $1 \mathrm{mo}$ \\
\hline Physical appearance & Yellow colour & No change & Yellow colour & No change \\
\hline \multirow[t]{2}{*}{ Drug Content (\%)* } & 92.10 & 91.73 & 92.10 & 91.00 \\
\hline & \pm 0.11 & \pm 0.60 & \pm 0.11 & \pm 0.12 \\
\hline \multirow[t]{2}{*}{ Drug Release (\%)* } & $51.94 \pm$ & 52.42 & 51.94 & 52.00 \\
\hline & 0.28 & \pm 0.38 & \pm 0.28 & \pm 0.99 \\
\hline
\end{tabular}

*Values are expressed as mean $\pm \mathrm{SD}(\mathrm{n}=3)$

\section{Stability study}

The stability of optimized pellet formulation was studied for 1 mo and results are evident in table 8 . From the data, no major change was observed in the appearance, drug content and drug release. This indicated the stability of the formulation at the test temperatures.

\section{CONCLUSION}

$\mathrm{Cu}$-SD pellets were prepared by extrusion spheronization technique and the optimization of the formulation was performed by $3^{2}$ full factorial design. Formulation of $\mathrm{Cu}-\mathrm{SD}$ was confirmed from FTIR and DSC studies. The SD was found to increase the Cu solubility and dissolution significantly. The optimized $\mathrm{Cu}$-SD pellets were spherical with narrow size distribution and indicated significant enhancement in $\mathrm{Cu}$ dissolution. The formulation was stable and the process was robust as confirmed from validation results. Conclusively, $\mathrm{Cu}-\mathrm{SD}$ pellets presents a promising approach indicating an improvement in $\mathrm{Cu}$ dissolution.

\section{AUTHORS CONTRIBUTIONS}

All the authors have contributed equally.

\section{CONFLICT OF INTERESTS}

Authors declare no conflict of interest.

\section{REFERENCES}

1. Girish C, Koner BC, Jayanthi S, Ramachandra Rao K, Rajesh B, Pradhan SC. Hepatoprotective activity of picroliv, curcumin and ellagic acid compared to silymarin on paracetamol-induced liver toxicity in mice. Fundam Clin Pharmacol 2009;23:735-45.

2. Shehzad A, Rehman G, Lee YS. Curcumin in inflammatory diseases. BioFactors 2013;39:69-77.

3. Gangwar RK, Tomar GB, Dhumale VA, Zinjarde S, Sharma RB, Datar S. Curcumin conjugated silica nanoparticles for improving bioavailability and its anticancer applications. J Agric Food Chem 2013;61:9632-7.

4. Pulido Moran M, Moreno Fernandez J, Ramirez Tortosa C, Ramirez Tortosa MC. Curcumin and health. Molecules 2016;21:1-22.

5. Anand P, Kunnumakkara AB, Newman RA, Aggarwal BB. Bioavailability of curcumin: problems and promises. Mol Pharmaceutics 2007;4:807-18.

6. Bikiaris DN. Solid dispersions, Part II: New strategies in manufacturing methods for dissolution rate enhancement of poorly water-soluble drugs. Expert Opin Drug Delivery 2011;8:1663-80.

7. $\mathrm{Xu} \mathrm{D,} \mathrm{Wang} \mathrm{S,} \mathrm{Jin} \mathrm{J,} \mathrm{Mei} \mathrm{X,} \mathrm{Xu} \mathrm{S.} \mathrm{Dissolution} \mathrm{and} \mathrm{absorption}$ researches of curcumin in solid dispersions with the polymers PVP. Asian J Pharmacodynamics Pharmacokinetics 2006;6:343-9.

8. Tripodo G, Pasut G, Trapani A, Mero A, Lasorsa FM, Chlapanidas $\mathrm{T}$, et al. Inulin-d- $\alpha$-tocopherol succinate (INVITE) nanomicelles as a platform for effective intravenous administration of curcumin. Biomacromolecules 2015;16:550-7.

9. Li J, Lee IW, Shin GH, Chen X, Park HJ. Curcumin-eudragit $®$ EPO solid dispersion: a simple and potent method to solve the problems of curcumin. Eur J Pharm Biopharm 2015;94:322-32.

10. Dewangan AK, Mazumder S, Perumal Y, Chopra K, Mazumder S. Preparation, characterization and anti-inflammatory effects of curcumin loaded carboxymethyl cellulose acetate butyrate nanoparticles on adjuvant induced arthritis in rats. J Drug Delivery Sci Technol 2017;41:269-79.

11. Fan N, He Z, Ma P, Wang X, Li C, Sun J, et al. Impact of HPMC on inhibiting crystallization and improving permeability of curcumin amorphous solid dispersions. Carbohydr Polym 2018;181:543-50.

12. Jagadeesan R, Radhakrishnan M. Novel approaches in the preparation of solid dispersion on solubility: a review. Int J Pharm Pharm Sci 2013;5:1000-4.

13. Seo SW, Han HK, Chun MK, Choi HK. Preparation and pharmacokinetic evaluation of curcumin solid dispersion using solutol ® HS15 as a carrier. Int J Pharm 2012;424:18-25.

14. Sharma A, Jain CP. Solid dispersion: a promising technique to enhance solubility of poorly water-soluble drug. Int J Drug Delivery 2011;1:149-70.

15. Parikh A, Kathawala K, Song Y, Zhou XF, Garg S. Curcuminloaded self-nanomicellizing solid dispersion system: part I: development, optimization, characterization, and oral bioavailability. Drug Delivery Transl Res 2018;8:1389-405.

16. Radjaram A, Fuad Hafid A, Setyawan D. Dissolution enhancement of curcumin by hydroxypropyl- $\beta$-cyclodextrin complexation. Int J Pharm Pharm Sci 2013;5:401-5.

17. Kurmi R, Mishra DK, Jain DK. Solid dispersion: a novel means of solubility enhancement. J Critical Rev 2016;3:1-8.

18. Saffoon N, Uddin R, Huda NH, Sutradhar KB. Enhancement of oral bioavailability and solid dispersion: a review. J Appl Pharm Sci 2011;1:13-20.

19. Patil AN, Shinkar DM, Saudagar RB. Review article: solubility enhancement by solid dispersion. Int J Curr Pharm Res 2017;9:15-8.

20. Pratap Singh D, Joshi Hanumanthachar K, Bharathi G. Enhancement of aqueous solubility of curcumin by solid dispersion technology. World J Pharm Pharm Sci 2015;2:4109-20.

21. Li B, Konecke S, Wegiel LA, Taylor LS, Edgar KJ. Both solubility and chemical stability of curcumin are enhanced by solid dispersion in cellulose derivative matrices. Carbohydr Polym 2013;98:1108-16.

22. Setthacheewakul S, Mahattanadul S, Phadoongsombut N, Pichayakorn W, Wiwattanapatapee R. Development and evaluation of self-microemulsifying liquid and pellet formulations of curcumin, and absorption studies in rats. Eur J Pharm Biopharm 2010;76:475-85.

23. Fousteris E, Tarantili PA, Karavas E, Bikiaris D. Poly(vinyl pyrrolidone)-poloxamer-188 solid dispersions prepared by hot 
melt extrusion: thermal properties and release behavior. J Therm Anal Calorim 2013;113:1037-47.

24. Najmuddin M, Khan T, Majed A, Shelar S, Patel V. Enhancement of dissolution rate of ketoconazole by solid dispersion technique. Int J Pharm Pharm Sci 2010;2:132-6.

25. Gangurde AB, Kundaikar HS, Javeer SD, Jaiswar DR, Degani MS, Amin PD. Enhanced solubility and dissolution of curcumin by a hydrophilic polymer solid dispersion and its insilico molecular modeling studies. J Drug Delivery Sci Technol 2015;29:226-37.

26. Boddu P, Cherakapu VL, Ponukumati UD. Application of solid dispersion technique in solubility and dissolution rate enhancement of nateglinide. Asian J Pharm Clin Res 2017;10:231-8.
27. Wakeham S, Heung S, Lee J, Sadowski CA. Beyond equality: providing equitable care for persons with disabilities. Can Pharm J 2017;150:251-8.

28. United States Pharmacopeia and National Formulary (USP 30 $\mathrm{NF}$ 25). Rockville, MD: United States Pharmacopeial Convention; 2007.

29. Bharti VP, Attal VR, Munde AV, Birajdar AS, Bais S. Strategies to enhance solubility and dissolution of a poorly water soluble drug. J Innovations Pharm Biol Sci 2015;2:481-94.

30. Paradkar A, Ambike AA, Jadhav BK, Mahadik KR Characterization of $\mathrm{Cu}$-PVP solid dispersion obtained by spray drying. Int J Pharm 2004;271:281-6. 